Acta Theriologica 39 (3): 279-287, 1994.

PL ISSN 0001-7051

\title{
Home range, habitat selection and activity of the red fox in a Mediterranean coastal ecotone
}

\author{
Paolo CAVALLINI and Sandro LOVARI*
}

\begin{abstract}
Cavallini P. and Lovari S. 1994. Home range, habitat selection and activity of the red fox in a Mediterranean coastal ecotone. Acta theriol. 39: 279-287.

Ranging behaviour and activity of five ( 2 females, 3 males) red foxes Vulpes vulpes (Linnaeus, 1758) in the Mediterranean coastal area of Maremma Natural Park (central Italy; an area of great habitat diversity) are described. One female ranged over a very small area and had diurnal activity rhythms. For other foxes, home range size $(100 \%$ minimum convex polygon) varied between 86 and 485 ha (larger than fox ranges in urban areas and smaller than in northern or homogeneous areas), and core areas (50\% harmonic mean) between 4.0 and 13.7 ha. Habitat diversity within home ranges was significantly higher than that of the overall area. Within their home ranges, foxes selected scrubwood for resting. When active, they showed individual differences in habitat selection. Peak activity was between $20.00 \mathrm{~h}$ and $22.00 \mathrm{~h}$, but foxes were active also during the day.

Department of Evolutionary Biology, Ethology and Behavioural Ecology Group, University of Siena, via Mattioli 4, 53100 Siena, Italy

Key words: Vulpes vulpes, home range, activity, habitat selection
\end{abstract}

\section{Introduction}

The red fox Vulpes vulpes (Linnaeus, 1758) is one of the most widespread mammals (Zimen 1980b). Its ecology and behaviour have been studied extensively in central and northern Europe (Zimen 1980a) and North America (Ables 1975), but few studies have been conducted in the Mediterranean region (Amores 1975, Reynolds 1979, Prigioni and Tacchi 1991). In most previous studies, fox populations under study were rarely free from human interference, either by hunting or by manipulating the environment. Because of high variability in size of home range (10-3420 ha; e.g. Jones and Theberge 1982, Voigt and Macdonald 1984, Lovari et al. 1991) geographical and individual variation is expected. As a rule, foxes are most abundant in mixed, heterogeneous, fragmented or discontinuous habitats (Ables 1975, Lloyd 1975), and select mosaic or shrub areas over homogeneous forests or open areas (Jones and Theberge 1982, Nakazono 1989). Inter-

* Requests for reprints should be sent to Sandro Lovari 
ference competition by other canids, however, may change this pattern (Theberge and Wedeles 1989). In the coastal ecotone of the Maremma Natural Park the diet of the red fox is varied, consisting mainly of fruits (especially juniper berries) and arthropods (especially Orthoptera and Coleoptera; Ciampalini and Lovari 1985, Calisti et al. 1990), and food consumption is well correlated with the availability of these resources. Habitat use is related to both the local availability and dispersion of food (Cavallini and Lovari 1991). In simple environments, where resources are exclusively concentrated in particular areas, individual variation in the home range size of carnivores has been explained by the distribution of key habitats. Home ranges encompass similar areas of "fruitful" habitat, but different areas of "useless" habitats (red fox - Macdonald 1981, arctic fox - Hersteinsson and Macdonald 1982, European badger - Kruuk and Parish 1982, Blanford's fox - Geffen et al. 1992b). Where several resources are available at the same time in different habitats, predictions are more difficult (Carr and Macdonald 1986). We hypothesise that in an ecotonal area with a high diversity of food resources foxes will: (1) select habitat diversity per se (thus obtaining access to a wider variety of food resources) rather than any particular habitat type; (2) show large individual differences in habitat selection. In comparatively small home ranges, where travelling costs are negligible (Corts and Lindzey 1984, Geffen et al. 1992a), habitat selection while resting will be independent from feeding areas, and will be determined by cover availability.

\section{Study area}

An ecotonal area in the centre of the Maremma Natural Park $\left(9,800\right.$ ha; $\left.42^{\circ} 39^{\prime} \mathrm{N}, 11^{\circ} 05^{\prime} \mathrm{E}\right)$, Grosseto County, along the Thyrrenian coastline, central Italy was selected for this study. The Park (established in 1975) is one of the last stretches of undisturbed Tyrrhenian coastline, and includes wetlands and wooded hills. Owing to the great environmental diversity, it is very rich in wildlife, both mammals (e.g. wild boar Sus scrofa, fallow deer Dama dama, roe deer Capreolus capreolus, badger Meles meles, martens Martes spp., and porcupine Hystrix cristata) and birds (especially abundant are the jay Garrulus glandarius and other scrubwood passerines, and wetland migratory birds, e.g. Arrigoni et al. 1976). The main habitats in the study area were: (1) very thick scrubwood (92-100\% total cover; mainly composed by Quercus ilex, with Arbutus unedo, Phillyrea latifolia, Erica arborea, Pistacia lentiscus), (2) meadow (55-92\% total cover; mainly composed by a wide and variable array of grasses and forbs, with very sparse bushes of Rosmarinus officinalis, Cistus monspeliensis, Erica multiflora), (3) pinewood (80-100\% total cover; thick bush of Phillyrea angustifolia, Erica multiflora, Myrtus communis and Juniperus oxycedrus under an overstorey of Pinus pinea, $P$. pinaster and $P$. halepensis), (4) sandy dune (15-60\% total cover; abundant juniper Juniperus oxycedrus and sparse grasses), (5) sandy beach (almost devoid of vegetation), (6) olive grove (Olea europaea with an understorey of grasses and forbs), and (7) marsh (flooded in winter; dominated by Juncus maritimus) (Arrigoni et al. 1985). There was little human interference with vegetation or wildlife, except limited cutting of the scrubwood and seasonal tourism mainly confined to the beach. We estimated that about 10 adult foxes lived in the area (Cavallini and Lovari 1991). Average weekly temperatures ranged from 4.5 to $28^{\circ} \mathrm{C}$; rainfall was scarce (average of $648 \mathrm{~mm} /$ year in the period 1955-1974) and concentrated in winter (Cavallini and Lovari 1991). 


\section{Methods}

From November 1985 through December 1986, five adult ( $>1$ year) foxes ( 3 males, 2 females) were captured, fitted with radiocollars and radiotracked at close range $(<200 \mathrm{~m})$ for $48 \mathrm{~h} /$ week. A hand-held, three-element Yagi antenna and a portable receiver were used. Tracking periods ( $8 \mathrm{~h}$ each) were distributed evenly during the $24 \mathrm{~h}$. Time to independence of successive locations was evaluated by a biological ( $\geq$ double the time necessary to cross the entire fox range at average speed) rather than a statistical method (Swihart and Slade 1985, Solow 1989). Therefore, one location per animal was recorded every $2 \mathrm{~h}$, which agrees with other estimates for the same species (Harris et al. 1990). From sightings of collared animals while radiotracking, error radii were $<25 \mathrm{~m}$ in most conditions. For each fix, activity (basing on signal amplitude fluctuations, Garshelis and Pelton 1980) and habitat type were recorded. Because none of the current measures of the home range size is free of problems (e.g. Harris et al. 1990) and also to make possible comparisons with past and future studies, four methods were used to calculate home range size: harmonic mean (Dixon and Chapman 1980; with Spencer and Barrett 1984 modification); kernel analysis (Worton 1989); minimum convex polygon (Hayne 1949), both including all the locations and excluding the $5 \%$ of active fixes farthest from the harmonic centre; and grid method (Voigt and Tinline 1980). Based on the accuracy of fixes, a square size of 0.39 ha was used. Core areas were evaluated by the harmonic mean method (50\% isopleth). The MicroComputer Program for the Analysis of Animal Loctions (MCPAAL; Stüwe and Blohwiak 1989) was used for home range size computation. The distribution of habitats in the study area was plotted on a map (1:5,000 scale), and the areas occupied by each habitat were measured. Habitat selection was evaluated at two levels: the proportion of each habitat type within each home range was compared with its availability in a reference area (i.e. the minimum rectangular area encompassing the home ranges of all radiotracked foxes; second-order selection of Johnson 1980), and the use (i.e. percentage of fixes) was compared with the availability of each type of habitat within the home range (third-order selection of Johnson 1980). Analyses were conducted at the individual level, because Thomas and Taylor (1990) and Harris et al. (1990) have shown that pooling data across individuals makes it difficult to evaluate the conclusions. Significant differences between use and abundance of habitats were determined with the $\chi^{2}$-test and the Bonferroni confidence intervals (Neu et al. 1974, Byers et al. 1984). Separate analyses were conducted for active and inactive locations, because the determinants of habitat selection are likely different for a foraging and for a resting or sleeping fox. Habitat diversity was evaluated by the Shannon-Wiener index. The difference between the habitat diversity of the overall area and that of the foxes has been evaluated by the test for difference between two diversity indices (Zar 1984). To evaluate activity rhythms the percentage of locations in which the fox was active (in total locations) was used.

\section{Results}

Altogether 3,780 locations were recorded for 5 foxes. Less than $5 \%$ of fixes were missing (i.e. the animal was not found when searched for) for each of the collared foxes (range 1.1-4.3\%). With the exception of one female, ranging over a small area (15-43 ha, according to various computing methods), home range size varied from 62 to 461 ha (harmonic mean) and from 86 to 485 ha (minimum convex polygon), without differences between the sexes (Mann-Whitney: $p>0.3$; Table 1). However, study foxes used only a small proportion of their harmonic mean or polygon home ranges (31-70 ha, grid method; $6.6-29.1 \%$ of minimum convex polygon). Excluding the 5\% of locations farthest from the harmonic centre, the range size become considerably smaller ( $80-230$ ha). Although ranges of foxes 
Table 1. Home range sizes (ha) of foxes in the Maremma Natural Park, Italy. See text for references to computational methods. Id - sex and identification number of individual foxes. ${ }^{a}$ two home ranges occupied sequentially (see text), ${ }^{b}$ probably underestimated because of small number of locations, $n$ - number of locations.

\begin{tabular}{|c|c|c|c|c|c|c|c|c|}
\hline \multirow[t]{2}{*}{ Id } & \multirow[t]{2}{*}{ Tracking period } & \multirow[t]{2}{*}{$n$} & \multicolumn{2}{|c|}{$\begin{array}{l}\text { Harmonic } \\
\text { mean }\end{array}$} & \multirow{2}{*}{$\begin{array}{c}\begin{array}{c}\text { Kernel } \\
\text { analysis }\end{array} \\
95 \%\end{array}$} & \multicolumn{2}{|c|}{$\begin{array}{l}\text { Minimum convex } \\
\text { polygon }\end{array}$} & \multirow[t]{2}{*}{ Grid } \\
\hline & & & $95 \%$ & $50 \%$ & & $100 \%$ & $95 \%$ & \\
\hline M1 & $4 / 11 / 85-20 / 12 / 86$ & 1332 & 62.2 & 10.3 & 73.6 & 193.8 & 91.1 & 56.3 \\
\hline \multirow[t]{2}{*}{$\mathrm{M} 2^{\mathrm{a}}$} & $4 / 11 / 85-24 / 1 / 86$ & 163 & 394.9 & 4.0 & 219.8 & 86.3 & 79.8 & $31.3^{\mathrm{b}}$ \\
\hline & & & 461.4 & 13.7 & 433.1 & 388.5 & 233.0 & \\
\hline M3 & $26 / 1-20 / 12 / 86$ & 1116 & 62.4 & 5.3 & 73.3 & 257.4 & 93.4 & 54.3 \\
\hline F1 & $4 / 11-20 / 12 / 85$ & 153 & 29.9 & 0.4 & 37.4 & 42.6 & 19.4 & $14.8^{\mathrm{b}}$ \\
\hline F2 & $11 / 2-20 / 12 / 86$ & 1016 & 316.8 & 12.0 & 297.5 & 484.8 & 226.1 & 69.5 \\
\hline
\end{tabular}

Table 2. Habitat use by foxes in the Maremma Natural Park, Italy. Habitats used significantly $(p<0.05$, Bonferroni confidence intervals) more or less than expected are indicated with + or -, $n$ - number of locations.

\begin{tabular}{lllllll}
\hline Id Scrubwood & Meadow Pinewood Dune & Olive grove & Marsh & $n$ \\
\hline
\end{tabular}

Proportion in home ranges (grid method) compared to proportion in study area

$\begin{array}{lllllllr}\text { Study area } & 0.57 & 0.18 & 0.08 & 0.08 & 0.04 & 0.05 & \\ \text { M1 } & 0.54 & 0.14 & 0.10 & 0.08 & 0.12+ & 0.03 & 1332 \\ \text { M2 } & 0.54 & 0.05- & 0.15 & 0.13 & 0.05 & 0.09 & 163 \\ \text { M3 } & 0.37- & 0.13 & 0.19+ & 0.16 & 0.08 & 0.07 & 1116 \\ \text { F1 } & 0.21- & 0.32 & 0.45+ & 0.03 & 0 & 0 & 153 \\ \text { F2 } & 0.30- & 0.26 & 0.12 & 0.13 & 0.19+ & 0 & 1016 \\ \text { Average } & 0.39 & 0.18 & 0.20 & 0.11 & 0.09 & 0.04 & \end{array}$

Proportion of active locations compared to proportion in home range

$\begin{array}{lllllllr}\text { M1 } & 0.48- & 0.32+ & 0.03- & 0.03- & 0.13 & <0.01- & 724 \\ \text { M2 } & 0.60 & 0.05- & 0.15 & 0.14 & 0.03 & 0.04 & 79 \\ \text { M3 } & 0.48+ & 0.07- & 0.21 & 0.16 & 0.03- & 0.05 & 599 \\ \text { F1 } & 0.26 & 0.28 & 0.40 & 0.06 & 0 & 0 & 53 \\ \text { F2 } & 0.26 & 0.35 & 0.20+ & 0.13 & 0.07 & 0 & 463 \\ \text { Average } & 0.42 & 0.21 & 0.20 & 0.10 & 0.05 & 0.02 & \end{array}$

Proportion of inactive locations compared to proportion in home range

\begin{tabular}{lllllrrrr} 
M1 & $0.92+$ & $0.08-$ & 0 & 0 & $<0.01-$ & $<0.01-$ & 608 \\
M2 & 0.63 & 0 & 0.09 & 0.19 & 0.02 & 0.06 & 84 \\
M3 & $0.75+$ & 0 & 0.23 & $<0.01-$ & 0 & $0.02-$ & 517 \\
F1 & $0.89+$ & $0.04-$ & $0.06-$ & $0.01-$ & 0 & 0 & 100 \\
F2 & $0.88+$ & $0.01-$ & $0.01-$ & $0.02-$ & $0.08-$ & 0 & 553 \\
Average & 0.81 & 0.03 & 0.08 & 0.05 & 0.02 & 0.02 & \\
\hline
\end{tabular}


tracked for the longer periods were remarkably stable, one of the males (M2) occupied first a range in the centre of the study area (harmonic mean $=395 \mathrm{ha}$ ), then, in November (the usual dispersal period, e.g. Zimen 1984) moved to a larger, disjunct one (harmonic mean $=461 \mathrm{ha})$. Core areas $(50 \%$ harmonic mean) ranged from 4.0 to 13.7 ha (Table 1). The proportion of scrubwood in the home range was less (M3, F1, F2) or equal (M1, M2) to that in the study area (Table 2). Pinewood (M3, F1) or olive grove (M1, F2) were over-represented in the home ranges. The proportions of other habitats were similar to those in the study area, with the exception of the meadow, which was under-represented in the range of M2 (Table 2). As a result, diversity of habitats within home ranges was higher than that of the overall area (Shannon-Wiener index for the study area $=0.57$; average for home ranges of foxes $=0.68 ; t=2.32, p<0.03$ ). Active foxes differed in habitat use with no consistent trend across individuals: over-utilized habitats were meadow for M1, scrubwood for M3, and pinewood for F2; under-utilized habitats were scrubwood for M1, meadow for M2 and M3, and pinewood for M1; dune, olive grove, and marsh were never over-utilized (under-utilized or not used at all by some individuals; Table 2). Foxes consistently over-utilized scrubwood (the habitat with the densest cover) for resting (with one exception), under-utilizing or not
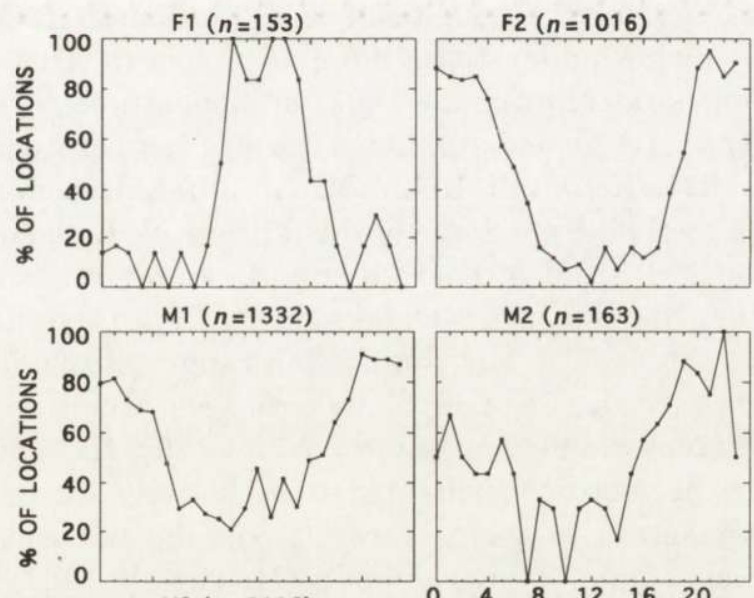

M2 $(n=163)$
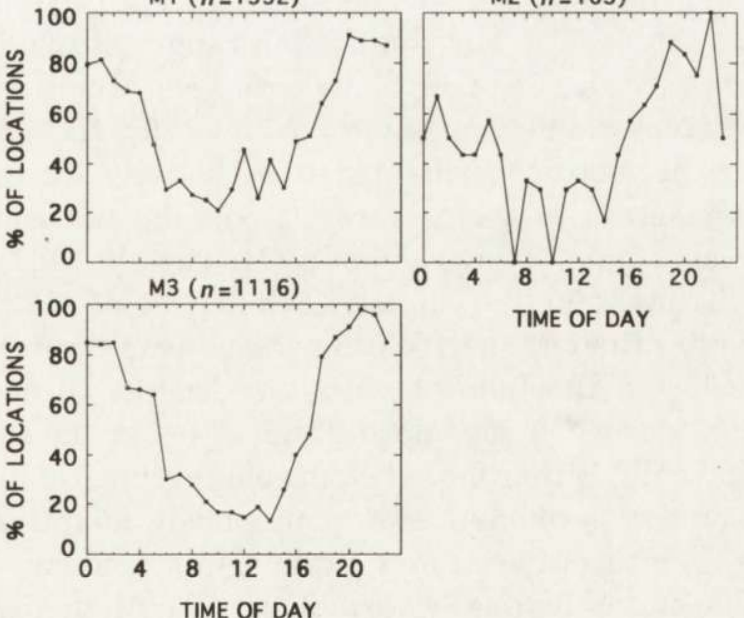

TIME OF DAY

Fig. 1. Activity rhythms (percentage of active locations in total locations) of five adult foxes in the Maremma Natural Park, Italy. Symbols (M, F; 1, 2, 3) indicate sex and individual number of foxes (as in Tables 1 and 2). $n$-number of locations. 
using most of the other habitats (Table 2). Total activity summed to about $50 \%$ of the time $(\mathrm{M} 1=55.0 \%, \mathrm{M} 2=48.5 \%, \mathrm{M} 3=53.7 \%, \mathrm{~F} 2=45.6 \%) . \mathrm{F} 1$ was active only $34.6 \%$ of the time, significantly less than the other animals $(\chi 2=7.3, p=0.006$ ). Furthermore her activity pattern was negatively correlated with that of each of the other foxes (Spearman rank correlation, $r_{\mathrm{s}}<-0.48, p<0.02$ ), whereas all other foxes had coincident activity rhythms $\left(r_{\mathrm{s}}>0.65, p<0.001\right)$. Indeed, $\mathrm{F} 1$ was found dead in poor physical conditions during the study period. We therefore excluded the data of this animal from the analyses. Usually activity was high during the night $(73.6 \% \pm 11.5 \mathrm{SD}$ of total active fixes were recorded between sunset and sunrise), starting around $16.00-18.00 \mathrm{~h}$ and ceasing around $06.00-08.00 \mathrm{~h}$, but foxes were also active during the day $(26.4 \% \pm 7.3 \mathrm{SD}$ of total active fixes were recorded between sunrise and sunset). The maximum activity levels, close to $100 \%$ of fixes, were reached between 20.00 and $22.00 \mathrm{~h}$ (Fig. 1).

\section{Discussion}

The mean home range size for red foxes in this Mediterranean ecotone ( 282 ha $\pm 141 \mathrm{SD}$, minimum convex polygon) was much larger than that reported for urban or suburban foxes (e.g. Harris 1980, Voigt and Macdonald 1984, Doncaster and Macdonald 1991), much smaller than those of northern areas (e.g. Jones and Theberge 1982, Voigt and Macdonald 1984) or homogeneous neighbour habitat (pinewood, Lovari et al. 1994), and similar to those of temperate or woodland areas (e.g. Artois et al. 1990, Cavallini 1992). Minor differences may be ascribed to different computing methods (e.g. some of the authors excluded occasional forays). Unfortunately, almost all studies reported only the minimum convex polygon size (or some modification thereof), whereas no study (except Cavallini 1992) reported the harmonic mean values. The harmonic mean ranges of two foxes were similar to those reported for a rural area of Japan, whereas the others were much smaller. All core areas were much smaller (average $=9$ ha vs 39.5 ha; Cavallini 1992). The foxes in Maremma therefore concentrated their activity in a small area, while maintaining regular access to a large area. Foxes did not consistently select a particular habitat, as in simpler environments (Macdonald 1981, Hersteinsson and Macdonald 1982, Kruuk and Parish 1982, Geffen et al. 1992b), but included heterogeneous areas in their ranges. Within their home range, all foxes strongly and consistently selected the habitat with the densest cover for resting. This behaviour is unexpected, when considering that foxes in the area have not been hunted for about 10 years. Either more favourable thermic conditions (cf Cavallini and Lovari 1991) or the permanence of a previously adaptive behaviour (with either a genetic or a cultural basis) may explain this tendency. On the contrary, foxes showed flexible and individually variable strategies for the selection of habitat used for feeding. Our results suggest that the resource-dispersion hypothesis (Macdonald 1983) cannot explain ranging behaviour in a complex environment with several productive habitats, if only food resources are considered. 
The fox is described as a predominantly nocturnal animal (Ables 1975, Maurel 1980, Artois 1985, Blanco 1986), with seasonal variation (Ables 1975, Cavallini and Lovari 1991). Some papers report of a higher activity during the day (Eguchi and Nakazono 1980, Phillips and Catling 1991, Lovari et al. 1994). The diurnal activity of one female found in this study has a parallel in the inversion of activity rhythms shown by a female in Australia, attributed to breeding (Phillips and Catling 1991). In our case, the poor physical conditions and the very small home range of the diurnal female rather suggest an attempt of minimizing direct confrontation with the more fit individuals. Furthermore, the tracking period of this female was outside the breeding season. A quantitative comparison of our results with those of other studies is difficult because of the different techniques used and the lack of other relevant data (e.g. food habits, hunting regime) for many areas. In our study area (where hunting is forbidden and disturbance is limited), foxes are more diurnal when eating diurnal insects, and more nocturnal when eating fruits, which are available for $24 \mathrm{~h}$ (Cavallini and Lovari 1991). Night time activity may be favoured by foxes, but they can switch to diurnal activity when induced by social or trophic factors.

Acknowledgements: We wish to thank the Maremma Natural Park staff (the director I. Boschi, the wardens and other personnel) for their kind collaboration; M. Calisti, E. Bindi, and especially G. Crema and M. Lucherini for their extensive help in the field work; the Azienda Agricola di Alberese (G. Tonelli) and the Grosseto Municipality (G. Pasquale) for lodging facilities; A. Frate and R. Cavallini for encouragement; M. Stüwe (Smithsonian institution) for a copy of MCPAAL programme. Suggestions by D. W. Macdonald, R. T. Bowyer and two anonymous referees improved the quality of this paper. Financial support was granted by the Maremma Natural Park to S. Lovari.

\section{References}

Ables E. D. 1975. Ecology of the red fox in North America. [In: The wild canids. Their systematics, behavioral ecology and evolution. M. W. Fox, ed]. Van Nostrand Reinhold Co., New York: 216-236.

Amores F. 1975. Diet of the red fox (Vulpes vulpes) in the western Sierra Morena (south Spain). Doñana Acta Vertebrata 2: 221-239.

Arrigoni P. V., Gellini R., Innamorati M., Lenzi Grillini C., Piussi P., Sartori G., Lovari S., Renzoni A. and Sanesi G. 1976. Relazione al Consorzio per l'istituzione del Parco della Maremma. Informatore Botanico Italiano 8: 283-324.

Arrigoni P. V., Nardi E. and Raffaelli M. 1985. La vegetazione del parco naturale della Maremma (Toscana). Università degli Studi di Firenze, Dipartimento di Biologia Vegetale, Firenze: 1-39.

Artois M. 1985. Utilization de l'espace et du temps chez le renard (Vulpes vulpes) et le chat forestier (Felis silvestris) en Lorraine. Gibier Faune Sauvage 3: 33-57.

Artois M., Aubert M. and Stahl P. 1990. Organisation spatiale du renard roux (Vulpes vulpes L., 1758) en zone d'enzootie de rage en Lorraine. Rev. Ecol. (Terre Vie) 45: 113-134.

Blanco J. C. 1986. On the diet, size and use of home range and activity patterns of a red fox in central Spain. Acta theriol. 31: 547-556.

Byers C. R., Steinhorst R. K. and Krausman P. R. 1984. Clarification of a technique for analysis of utilization - availability data. J. Wildl. Manage. 48: 1050-1053.

Calisti M., Ciampalini B., Lovari S. and Lucherini M. 1990. Food habits and trophic niche variation of the red fox Vulpes vulpes (L., 1758) in a Mediterranean coastal area. Rev. Ecol. (Terre Vie) 45: 309-320. 
Carr G. M. and Macdonald D. W. 1986. The sociality of solitary foragers: a model based on resource dispersion. Anim. Behav. 34: 1540-1549.

Cavallini P. 1992. On the ranging behaviour of red foxes in rural southern Japan. J. Mammal. 73: 321-325.

Cavallini P. and Lovari S. 1991. Environmental factors influencing the use of habitat in the red fox, Vulpes vulpes (L., 1758). J. Zool., Lond. 223: 323-339.

Ciampalini B. and Lovari S. 1985. Food habits and trophic niche overlap of the badger (Meles meles L.) and the red fox (Vulpes vulpes L.) in a Mediterranean coastal area. Z. Säugetierk. 50: 226-234.

Corts K. E. and Lindzey F. G. 1984. Basal metabolism and energetic cost of walking in cougars. J. Wildl. Manage. 48: 1456-1458.

Dixon K. R. and Chapman J. A. 1980. Harmonic mean measure of animal activity areas. Ecology 61: 1040-1044.

Doncaster C. P. and Macdonald D. W. 1991. Drifting territoriality in the red fox Vulpes vulpes. J. Anim. Ecol. 60: 423-439.

Eguchi K. and Nakazono T. 1980. Activity studies of Japanese red foxes, Vulpes vulpes japonica Gray. Jap. J. Ecol. 30: 9-17.

Garshelis D. L. and Pelton M. R. 1980. Activity of black bears in the Great Smoky Mountains National Park. J. Mammal. 61: 8-19.

Geffen E., Degen A. A., Kam M., Hefner R. and Nagy K. A. 1992a. Daily energy expenditure and water flux of free-living Blanford's foxes (Vulpes cana), a small desert carnivore. J. Anim. Ecol. 61: 611-617.

Geffen E., Hefner R., Macdonald D. W. and Ucko M. 1992b. Habitat selection and home range in the Blanford's fox, Vulpes cana: compatibility with the resource dispersion hypothesis. Oecologia 91: $75-81$.

Harris S. 1980. Home ranges and patterns of distribution of foxes (Vulpes vulpes) in an urban area, as revealed by radiotracking. [In: A handbook on biotelemetry and radiotracking. C. J. Amlaner and D. W. Macdonald, ed]. Pergamon Press, Oxford, U.K.: 685-690.

Harris S., Cresswell W. J., Forde P. G., Trewhella W. J., Woollard T. and Wray S. 1990. Home-range analysis using radiotracking data - a review of problems and techniques particularly as applied to the study of mammals. Mammal Rev. 20: 97-123.

Hayne W. D. 1949. Calculation of size of home range. J. Mammal. 30: 1-17.

Hersteinsson P. and Macdonald D. W. 1982. Some comparison between red and arctic foxes, Vulpes vulpes and Alopex lagopus, as revealed by radio tracking. Symp. zool. Soc. Lond. 49: 259-289.

Johnson D. H. 1980. The comparison of usage and availability measurements for evaluating resource preference. Ecology 61: 65-71.

Jones D. M. and Theberge J. B. 1982. Summer home range and habitat utilization of the red fox (Vulpes vulpes) in a tundra habitat, northwest British Columbia. Can. J. Zool. 60: 807-812.

Kruuk H. and Parish T. 1982. Factors affecting population density, group size and territory size of the European badger, Meles meles. J. Zool., Lond. 196: 31-39.

Lloyd H. G. 1975. The red fox in Britain. [In: The wild canids. Their systematics, behavioral ecology and evolution. M. W. Fox, ed]. Van Nostrand Reinhold Co., New York: 207-215.

Lovari S., Cavallini P., Crema G., Lazzeretti L., Lucherini M., Ricci Lucchi M. and Valier P. 1991. Environmental variables and the use of habitat of the red fox in the Maremma Natural Park, Italy. Hystrix 3: 21-29. [In Italian with English summary]

Lovari S., Valier P. and Ricci Lucchi M. 1994. Ranging behaviour and activity of red foxes in relation to environmental variables, in a Mediterranean mixed pinewood. J. Zool., Lond. 232: 323-339.

Macdonald D. W. 1981. Resource dispersion and the social organization of the red fox (Vulpes vulpes). Worldwide Furbearer Conference Proceedings, University of Maryland Press, Frostburg, MD: 918-949.

Macdonald D. W. 1983. The ecology of carnivore social behaviour. Nature 301: 379-384. 
Maurel D. 1980. Home range and activity rhythm of adult male foxes during the breeding season. [In: A handbook on biotelemetry and radiotracking. C. J. Amlaner and D. W. Macdonald, eds]. Pergamon Press, Oxford, U.K.: 697-701.

Nakazono T. 1989. The habitat utilization pattern of Japanese red fox, Vulpes vulpes japonica, in Kyushu. Honyurui Kagaku (Mammalian Science) 29: 51-62.

Neu C. W., Byers C. R. and Peek J. M. 1974. A technique for analysis of utilization - availability data. J. Wildl. Manage. 38: 541-545.

Phillips M. and Catling P. C. 1991. Home range and activity patterns of red foxes in Nadgee Nature Reserve. Wildl. Res. 18: 677-686.

Prigioni C. and Tacchi F. 1991. Trophic niche of the red fox Vulpes vulpes in the Ticino valley. Hystrix 3: $65-75$.

Reynolds P. 1979. Preliminary observations on the food of the fox (Vulpes vulpes L.) in the Camargue, with special reference to rabbit (Oryctolagus cuniculus L.) predation. Mammalia 43: 295-307.

Solow A. R. 1989. A randomization test for independence of animal locations. Ecology 70: 1546-1549.

Spencer W. D. and Barrett R. H. 1984. An evaluation of the harmonic mean measure for defining carnivore activity areas. Acta zool. Fenn. 171: 255-259.

Stüwe M. and Blohwiak C. E. 1989. McPAAL. Micro-computer Programs for the Analysis of Animal Locations. Ver. 2.0. Smithsonian Institution, Front Royal, VA, USA.

Swihart R. K. and Slade N. A. 1985. Testing for independence of observations in animal movements. Ecology 66: 1176-1184.

Theberge J. B. and Wedeles C. H. R. 1989. Prey selection and habitat partitioning in sympatric coyote and red fox populations, southwest Yukon. Can. J. Zool. 67: 1285-1290.

Thomas D. L. and Taylor E. J. 1990. Study designs and tests for comparing resource use and availability. J. Wildl. Manage. 54: 322-331.

Voigt D. R. and Macdonald D. W. 1984. Variation in the spatial and social behaviour of the red fox, Vulpes vulpes. Acta zool. Fenn. 171: 261-265.

Voigt D. R. and Tinline R. R. 1980. Strategies for analyzing radio tracking data. [In: A handbook on biotelemetry and radiotracking. C. J. Amlaner and D. W. Macdonald, eds]. Pergamon Press, Oxford, U.K.: 387-404.

Worton B. J. 1989. Kernel methods for estimating the utilization distribution in home-range studies. Ecology 70: 164-168.

Zar J. H. 1984. Biostatistical analysis. Second ed. Prentice-Hall, Inc., Englewood Cliffs, New Jersey: $1-718$.

Zimen E., ed. 1980a. The red fox. Biogeographica Vol. 18. W. Junk B.V. Publishers, The Hague, The Netherlands: 1-285.

Zimen E. 1980b. A short history of human attitudes towards the fox. [In: The red fox. Biogeographica Vol. 18. E. Zimen, ed]. W. Junk B.V. Publishers, The Hague, The Netherlands: 1-6.

Zimen E. 1984. Long range movements of the red fox, Vulpes vulpes L. Acta zool. Fenn. 171: 267-270.

Received 15 March 1994, accepted 30 June 1994. 